\title{
Multiple positive solutions for first-order impulsive singular integro-differential equations on the half line in a Banach space
}

\section{Yanlai Chen ${ }^{1 *}$ and Baoxia Qin²}

"Correspondence:

yanlaichen@126.com

1 School of Economics, Shandong

University, Jinan, Shandong 250100,

People's Republic of China

Full list of author information is

available at the end of the article

\begin{abstract}
In this paper, the author discusses the multiple positive solutions for an infinite three-point boundary value problem of first-order impulsive superlinear singular integro-differential equations on the half line in a Banach space by means of the fixed-point theorem of cone expansion and compression with norm type.

MSC: 45J05; 34G20; 47H10

Keywords: impulsive singular integro-differential equation in a Banach space; infinite three-point boundary value problem; fixed-point theorem of cone expansion and compression with norm type
\end{abstract}

\section{Introduction}

In recent years, multiple solutions of boundary value problems for impulsive differential equations in scalar spaces had been extensively studied (see, for example, [1-3]). In recent papers [4] and [5], Professor D. Guo discussed two infinite boundary value problems for $n$ th-order impulsive nonlinear singular integro-differential equations of mixed type on the half line in a Banach space. By constructing a bounded closed convex set, apart from the singularities, and using the Schauder fixed-point theorem, he obtained the existence of positive solutions for the infinite boundary value problems. But such equations are sublinear, and there are no results on existence of two positive solutions. Now, in this paper, we shall discuss the existence of two positive solutions for first-order superlinear singular equations by means of a different method, i.e., by using the fixed-point theorem of cone expansion and compression with norm type (see $[6,7])$, and the key point is to introduce a new cone $Q$.

Let $E$ be a real Banach space and $P$ be a cone in $E$, which defines a partial ordering in $E$ by $x \leq y$ if and only if $y-x \in P$. $P$ is said to be normal if there exists a positive constant $N$ such that $\theta \leq x \leq y$ implies $\|x\| \leq N\|y\|$, where $\theta$ denotes the zero element of $E$, and the smallest $N$ is called the normal constant of $P$. If $x \leq y$ and $x \neq y$, we write $x<y$. Let $P_{+}=P \backslash\{\theta\}$, i.e., $P_{+}=\{x \in P: x>\theta\}$. For details on cone theory, see [7]. 
Consider the infinite three-point boundary value problem for a first-order impulsive nonlinear singular integro-differential equation of mixed type on the half line in $E$ :

$$
\left\{\begin{array}{l}
u^{\prime}(t)=f(t, u(t),(T u)(t),(S u)(t)), \quad \forall t \in J_{+}^{\prime}, \\
\left.\Delta u\right|_{t=t_{k}}=I_{k}\left(u\left(t_{k}\right)\right) \quad(k=1,2,3, \ldots), \\
u(\infty)=\gamma u(\eta)+\beta u(0),
\end{array}\right.
$$

where $J=[0, \infty), J_{+}=(0, \infty), 0<t_{1}<\cdots<t_{k}<\cdots, t_{k} \rightarrow \infty, J_{+}^{\prime}=J_{+} \backslash\left\{t_{1}, \ldots, t_{k}, \ldots\right\}, f \in$ $C\left[J_{+} \times P_{+} \times P \times P, P\right], I_{k} \in C\left[P_{+}, P\right](k=1,2,3, \ldots), 0 \leq \gamma<1, \beta+\gamma>1, t_{m-1}<\eta<t_{m}$ (for some $m), u(\infty)=\lim _{t \rightarrow \infty} u(t)$ and

$$
(T u)(t)=\int_{0}^{t} K(t, s) u(s) d s, \quad(S u)(t)=\int_{0}^{\infty} H(t, s) u(s) d s,
$$

$K \in C\left[D, R_{+}\right], D=\{(t, s) \in J \times J: t \geq s\}, H \in C\left[J \times J, R_{+}\right], R_{+}$denotes the set of all nonnegative numbers. $\left.\Delta u\right|_{t=t_{k}}$ denotes the jump of $u(t)$ at $t=t_{k}$, i.e.,

$$
\left.\Delta u\right|_{t=t_{k}}=u\left(t_{k}^{+}\right)-u\left(t_{k}^{-}\right)
$$

where $u\left(t_{k}^{+}\right)$and $u\left(t_{k}^{-}\right)$represent the right and left limits of $u(t)$ at $t=t_{k}$, respectively. In the following, we always assume that

$$
\lim _{t \rightarrow 0^{+}}\|f(t, u, v, w)\|=\infty, \quad \forall u \in P_{+}, v, w \in P
$$

and

$$
\lim _{u \rightarrow \theta^{+}}\|f(t, u, v, w)\|=\infty, \quad \forall t \in J_{+}, v, w \in P
$$

(where $u \rightarrow \theta^{+}$means $u>\theta,\|u\| \rightarrow 0$ ), i.e., $f(t, u, v, w)$ is singular at $t=0$ and $u=\theta$. We also assume that

$$
\lim _{u \rightarrow \theta^{+}}\left\|I_{k}(u)\right\|=\infty \quad(k=1,2,3, \ldots)
$$

i.e., $I_{k}(u)(k=1,2,3, \ldots)$ are singular at $u=\theta$.

Let $P C[J, E]=\left\{u: u\right.$ is a map from $J$ into $E$ such that $u(t)$ is continuous at $t \neq t_{k}$, left continuous at $t=t_{k}$, and $u\left(t_{k}^{+}\right)$exists, $\left.k=1,2,3, \ldots\right\}$ and $B P C[J, E]=\{u \in P C[J, E]$ : $\left.\sup _{t \in J}\|u(t)\|<\infty\right\}$. It is clear that $B P C[, E]$ is a Banach space with norm

$$
\|u\|_{B}=\sup _{t \in J}\|u(t)\| .
$$

Let $B P C[, P]=\{u \in B P C[J, E]: u(t) \geq \theta, \forall t \in J\}$ and $Q=\left\{u \in B P C[, P]: u(t) \geq \beta^{-1}(1-\right.$ $\gamma) u(s), \forall t, s \in J\}$. Obviously, $B P C[J, P]$ and $Q$ are two cones in space $B P C[J, E]$ and $Q \subset$ $B P C[J, P] . u \in B P C[J, P] \cap C^{1}\left[J_{+}^{\prime}, E\right]$ is called a positive solution of the infinite three-point boundary value problem (1) if $u(t)>\theta$ for $t \in J$ and $u(t)$ satisfies (1). Let $Q_{+}=\{u \in Q$ : $\left.\|u\|_{B}>0\right\}$ and $Q_{p q}=\left\{u \in Q: p \leq\|u\|_{B} \leq q\right\}$ for $q>p>0$. 


\section{Several lemmas}

Let us list some conditions.

$$
\begin{gathered}
\left(\mathrm{H}_{1}\right) \sup _{t \in J} \int_{0}^{t} K(t, s) d s<\infty, \sup _{t \in J} \int_{0}^{\infty} H(t, s) d s<\infty \text { and } \\
\lim _{t^{\prime} \rightarrow t} \int_{0}^{\infty}\left|H\left(t^{\prime}, s\right)-H(t, s)\right| d s=0, \quad \forall t \in J .
\end{gathered}
$$

In this case, let

$$
k^{*}=\sup _{t \in J} \int_{0}^{t} K(t, s) d s, \quad h^{*}=\sup _{t \in J} \int_{0}^{\infty} H(t, s) d s .
$$

$\left(\mathrm{H}_{2}\right)$ There exist $a \in C\left[J_{+}, R_{+}\right]$and $g \in C\left[R_{++} \times R_{+} \times R_{+}, R_{+}\right]$such that

$$
\|f(t, u, v, w)\| \leq a(t) g(\|u\|,\|v\|,\|w\|), \quad \forall t \in J_{+}, u \in P_{+}, v, w \in P
$$

and

$$
a^{*}=\int_{0}^{\infty} a(t) d t<\infty
$$

where $R_{++}=\left\{x \in R_{+}: x>0\right\}$.

$\left(\mathrm{H}_{3}\right)$ There exist $\gamma_{k} \geq 0(k=1,2,3, \ldots)$ and $F \in C\left[R_{++}, R_{+}\right]$such that

$$
\left\|I_{k}(u)\right\| \leq \gamma_{k} F(\|u\|), \quad \forall u \in P_{+}(k=1,2,3, \ldots)
$$

and

$$
\gamma^{*}=\sum_{k=1}^{\infty} \gamma_{k}<\infty
$$

$\left(\mathrm{H}_{4}\right)$ For any $t \in J_{+}$and $r>p>0, f\left(t, P_{p r}, P_{r}, P_{r}\right)=\left\{f(t, u, v, w): u \in P_{p r}, v, w \in P_{r}\right\}$ and $I_{k}\left(P_{p r}\right)=\left\{I_{k}(u): u \in P_{p r}\right\}(k=1,2,3, \ldots)$ are relatively compact in $E$, where $P_{r}=\{u \in P$ : $\|u\| \leq r\}$ and $P_{p r}=\{u \in P: p \leq\|u\| \leq r\}$.

Remark Obviously, condition $\left(\mathrm{H}_{4}\right)$ is satisfied automatically when $E$ is finite dimensional.

Remark It is clear: If condition $\left(\mathrm{H}_{1}\right)$ is satisfied, then the operators $T$ and $S$ defined by (2) are bounded linear operators from $B P C[J, E]$ into $B P C[J, E]$ and $\|T\| \leq k^{*},\|S\| \leq h^{*}$; moreover, we have $T(B P C[, P]) \subset B P C[, P]$ and $S(B P C[, P]) \subset B P C[, P]$.

We shall reduce the infinite three-point boundary value problem (1) to an impulsive integral equation. To this end, we consider the operator $A$ defined by

$$
\begin{aligned}
(A u)(t)= & \frac{1}{\beta+\gamma-1}\left\{\int_{\eta}^{\infty} f(s, u(s),(T u)(s),(S u)(s)) d s\right. \\
& +(1-\gamma) \int_{0}^{\eta} f(s, u(s),(T u)(s),(S u)(s)) d s
\end{aligned}
$$




$$
\begin{aligned}
& \left.+\sum_{k=m}^{\infty} I_{k}\left(u\left(t_{k}\right)\right)+(1-\gamma) \sum_{k=1}^{m-1} I_{k}\left(u\left(t_{k}\right)\right)\right\} \\
& +\int_{0}^{t} f(s, u(s),(T u)(s),(S u)(s)) d s+\sum_{0<t_{k}<t} I_{k}\left(u\left(t_{k}\right)\right), \quad \forall t \in J .
\end{aligned}
$$

In what follows, we write $J_{1}=\left[0, t_{1}\right], J_{k}=\left(t_{k-1}, t_{k}\right](k=2,3,4, \ldots)$.

Lemma 1 Let cone $P$ be normal and conditions $\left(\mathrm{H}_{1}\right)-\left(\mathrm{H}_{4}\right)$ be satisfied. Then operator A defined by (6) is a continuous operator from $Q_{+}$into $Q$; moreover, for any $q>p>0, A\left(Q_{p q}\right)$ is relatively compact.

Proof Let $u \in Q_{+}$and $\|u\|_{B}=r$. Then $r>0$ and

$$
u(t) \geq \beta^{-1}(1-\gamma) u(s) \geq \theta, \quad \forall t, s \in J
$$

so,

$$
\|u(t)\| \geq N^{-1} \beta^{-1}(1-\gamma)\|u\|_{B}, \quad \forall t \in J
$$

where $N$ denotes the normal constant of cone $P$, and consequently,

$$
N^{-1} \beta^{-1}(1-\gamma) r \leq\|u(t)\| \leq r, \quad \forall t \in J
$$

By condition $\left(\mathrm{H}_{2}\right)$ and (8), we have

$$
\|f(t, u(t),(T u)(t),(S u)(t))\| \leq M a(t), \quad \forall t \in J,
$$

where

$$
M=\max \left\{g(x, y, z): N^{-1} \beta^{-1}(1-\gamma) r \leq x \leq r, 0 \leq y \leq k^{*} r, 0 \leq z \leq h^{*} r\right\},
$$

which implies the convergence of the infinite integral

$$
\int_{0}^{\infty} f(t, u(t),(T u)(t),(S u)(t)) d t
$$

and

$$
\left\|\int_{0}^{\infty} f(t, u(t),(T u)(t),(S u)(t)) d t\right\| \leq \int_{0}^{\infty}\|f(t, u(t),(T u)(t),(S u)(t))\| d t \leq M a^{*}
$$

On the other hand, by condition $\left(\mathrm{H}_{3}\right)$ and (8), we have

$$
\left\|I_{k}\left(u\left(t_{k}\right)\right)\right\| \leq D \gamma_{k} \quad(k=1,2,3, \ldots)
$$

where

$$
D=\max \left\{F(x): N^{-1} \beta^{-1}(1-\gamma) r \leq x \leq r\right\}
$$


which implies the convergence of the infinite series

$$
\sum_{k=1}^{\infty} I_{k}\left(u\left(t_{k}\right)\right)
$$

and

$$
\left\|\sum_{k=1}^{\infty} I_{k}\left(u\left(t_{k}\right)\right)\right\| \leq \sum_{k=1}^{\infty}\left\|I_{k}\left(u\left(t_{k}\right)\right)\right\| \leq D \gamma^{*} .
$$

It follows from (6), (11), and (14) that

$$
\begin{aligned}
\|(A u)(t)\| \leq & \frac{1}{\beta+\gamma-1}\left\{\int_{\eta}^{\infty}\|f(s, u(s),(T u)(s),(S u)(s))\| d s\right. \\
& +(1-\gamma) \int_{0}^{\eta}\|f(s, u(s),(T u)(s),(S u)(s))\| d s \\
& \left.+\sum_{k=m}^{\infty}\left\|I_{k}\left(u\left(t_{k}\right)\right)\right\|+(1-\gamma) \sum_{k=1}^{m-1}\left\|I_{k}\left(u\left(t_{k}\right)\right)\right\|\right\} \\
& +\int_{0}^{t}\|f(s, u(s),(T u)(s),(S u)(s))\| d s+\sum_{0<t_{k}<t}\left\|I_{k}\left(u\left(t_{k}\right)\right)\right\| \\
\leq & \frac{1}{\beta+\gamma-1}\left\{\int_{0}^{\infty}\|f(s, u(s),(T u)(s),(S u)(s))\| d s+\sum_{k=1}^{\infty}\left\|I_{k}\left(u\left(t_{k}\right)\right)\right\|\right\} \\
& +\int_{0}^{\infty}\|f(s, u(s),(T u)(s),(S u)(s))\| d s+\sum_{k=1}^{\infty}\left\|I_{k}\left(u\left(t_{k}\right)\right)\right\| \\
\leq & \frac{\beta+\gamma}{\beta+\gamma-1}\left\{\int_{0}^{\infty}\|f(s, u(s),(T u)(s),(S u)(s))\| d s+\sum_{k=1}^{\infty}\left\|I_{k}\left(u\left(t_{k}\right)\right)\right\|\right\} \\
\beta+\gamma-1 & \left(M a^{*}+D \gamma *\right), \forall t \in J,
\end{aligned}
$$

which implies that $A u \in B P C[J, P]$ and

$$
\|A u\|_{B} \leq \frac{\beta+\gamma}{\beta+\gamma-1}\left(M a^{*}+D \gamma^{*}\right) .
$$

Moreover, by (6), we have

$$
\begin{aligned}
(A u)(t) \geq & \frac{1}{\beta+\gamma-1}\left\{\int_{\eta}^{\infty} f(s, u(s),(T u)(s),(S u)(s)) d s\right. \\
& +(1-\gamma) \int_{0}^{\eta} f(s, u(s),(T u)(s),(S u)(s)) d s \\
& \left.+\sum_{k=m}^{\infty} I_{k}\left(u\left(t_{k}\right)\right)+(1-\gamma) \sum_{k=1}^{m-1} I_{k}\left(u\left(t_{k}\right)\right)\right\}, \quad \forall t \in J
\end{aligned}
$$


and

$$
\begin{aligned}
(A u)(t) \leq & \frac{1}{\beta+\gamma-1}\left\{\int_{\eta}^{\infty} f(s, u(s),(T u)(s),(S u)(s)) d s\right. \\
& +(1-\gamma) \int_{0}^{\eta} f(s, u(s),(T u)(s),(S u)(s)) d s \\
& \left.+\sum_{k=m}^{\infty} I_{k}\left(u\left(t_{k}\right)\right)+(1-\gamma) \sum_{k=1}^{m-1} I_{k}\left(u\left(t_{k}\right)\right)\right\} \\
& +\int_{0}^{\infty} f(s, u(s),(T u)(s),(S u)(s)) d s+\sum_{k=1}^{\infty} I_{k}\left(u\left(t_{k}\right)\right), \quad \forall t \in J .
\end{aligned}
$$

It is clear,

$$
\begin{aligned}
& \int_{0}^{\infty} f(s, u(s),(T u)(s),(S u)(s)) d s+\sum_{k=1}^{\infty} I_{k}\left(u\left(t_{k}\right)\right) \\
& \leq \frac{1}{1-\gamma}\left\{\int_{\eta}^{\infty} f(s, u(s),(T u)(s),(S u)(s)) d s+(1-\gamma) \int_{0}^{\eta} f(s, u(s),(T u)(s),(S u)(s)) d s\right. \\
& \left.\quad+\sum_{k=m}^{\infty} I_{k}\left(u\left(t_{k}\right)\right)+(1-\gamma) \sum_{k=1}^{m-1} I_{k}\left(u\left(t_{k}\right)\right)\right\}
\end{aligned}
$$

so, (17) and (18) imply

$$
\begin{aligned}
(A u)(t) \leq & \left\{\frac{1}{\beta+\gamma-1}+\frac{1}{1-\gamma}\right\}\left\{\int_{\eta}^{\infty} f(s, u(s),(T u)(s),(S u)(s)) d s\right. \\
& +(1-\gamma) \int_{0}^{\eta} f(s, u(s),(T u)(s),(S u)(s)) d s \\
& \left.+\sum_{k=m}^{\infty} I_{k}\left(u\left(t_{k}\right)\right)+(1-\gamma) \sum_{k=1}^{m-1} I_{k}\left(u\left(t_{k}\right)\right)\right\}, \quad \forall t \in J .
\end{aligned}
$$

It follows from (16) and (19) that

$$
\begin{aligned}
(A u)(t) & \geq \frac{1}{\beta+\gamma-1}\left(\frac{1}{\beta+\gamma-1}+\frac{1}{1-\gamma}\right)^{-1}(A u)(s) \\
& =\beta^{-1}(1-\gamma)(A u)(s), \quad \forall t, s \in J .
\end{aligned}
$$

Hence, $A u \in Q$, i.e., $A$ maps $Q_{+}$into $Q$.

Now, we are going to show that $A$ is continuous. Let $u_{n}, \bar{u} \in Q_{+},\left\|u_{n}-\bar{u}\right\|_{B} \rightarrow 0(n \rightarrow \infty)$. Write $\|\bar{u}\|_{B}=2 \bar{r}(\bar{r}>0)$ and we may assume that

$$
\bar{r} \leq\left\|u_{n}\right\|_{B} \leq 3 \bar{r} \quad(n=1,2,3, \ldots) .
$$

So, by (7),

$$
N^{-1} \beta^{-1}(1-\gamma) \bar{r} \leq\left\|u_{n}(t)\right\| \leq 3 \bar{r}, \quad \forall t \in J(n=1,2,3, \ldots)
$$


and

$$
N^{-1} \beta^{-1}(1-\gamma) \bar{r}<2 N^{-1} \beta^{-1}(1-\gamma) \bar{r} \leq\|\bar{u}(t)\| \leq 2 \bar{r}<3 \bar{r}, \quad \forall t \in J .
$$

Similar to (15), it is easy to get

$$
\begin{aligned}
& \left\|A u_{n}-A \bar{u}\right\|_{B} \\
& \leq \frac{\beta+\gamma}{\beta+\gamma-1}\left\{\int_{0}^{\infty}\left\|f\left(s, u_{n}(s),\left(T u_{n}\right)(s),\left(S u_{n}\right)(s)\right)-f(s, \bar{u}(s),(T \bar{u})(s),(S \bar{u})(s))\right\| d s\right. \\
& \left.\quad+\sum_{k=1}^{\infty}\left\|I_{k}\left(u_{n}\left(t_{k}\right)\right)-I_{k}\left(\bar{u}\left(t_{k}\right)\right)\right\|\right\} \quad(n=1,2,3, \ldots) .
\end{aligned}
$$

It is clear that

$$
f\left(t, u_{n}(t),\left(T u_{n}\right)(t),\left(S u_{n}\right)(t)\right) \rightarrow f(t, \bar{u}(t),(T \bar{u})(t),(S \bar{u})(t)) \quad \text { as } n \rightarrow \infty, \forall t \in J
$$

and, similar to (9) and observing (21) and (22), we have

$$
\begin{aligned}
& \left\|f\left(t, u_{n}(t),\left(T u_{n}\right)(t),\left(S u_{n}\right)(t)\right)-f(t, \bar{u}(t),(T \bar{u})(t),(S \bar{u})(t))\right\| \leq 2 \bar{M} a(t)=d(t), \\
& \quad \forall t \in J(n=1,2,3, \ldots) ; d \in L\left[J, R_{+}\right]
\end{aligned}
$$

where

$$
\bar{M}=\max \left\{g(x, y, z): N^{-1} \beta^{-1}(1-\gamma) \bar{r} \leq x \leq 3 \bar{r}, 0 \leq y \leq 3 k^{*} \bar{r}, 0 \leq z \leq 3 h^{*} \bar{r}\right\} .
$$

It follows from (24), (25), and the dominated convergence theorem that

$$
\lim _{n \rightarrow \infty} \int_{0}^{\infty}\left\|f\left(t, u_{n}(t),\left(T u_{n}\right)(t),\left(S u_{n}\right)(t)\right)-f(t, \bar{u}(t),(T \bar{u})(t),(S \bar{u})(t))\right\| d t=0
$$

On the other hand, for any $\epsilon>0$, we can choose a positive integer $j$ such that

$$
\bar{D} \sum_{k=j+1}^{\infty} \gamma_{k}<\epsilon
$$

where

$$
\bar{D}=\max \left\{F(x): N^{-1} \beta^{-1}(1-\gamma) \bar{r} \leq x \leq 3 \bar{r}\right\}
$$

And then, choose an positive integer $n_{0}$ such that

$$
\sum_{k=1}^{j}\left\|I_{k}\left(u_{n}\left(t_{k}\right)\right)-I_{k}\left(\bar{u}\left(t_{k}\right)\right)\right\|<\epsilon, \quad \forall n>n_{0} .
$$


From (27), (28), and observing condition $\left(\mathrm{H}_{3}\right)$ and (21), (22), we get

$$
\sum_{k=1}^{\infty}\left\|I_{k}\left(u_{n}\left(t_{k}\right)\right)-I_{k}\left(\bar{u}\left(t_{k}\right)\right)\right\|<\epsilon+2 \bar{D} \sum_{k=j+1}^{\infty} \gamma_{k}<3 \epsilon, \quad \forall n>n_{0},
$$

hence,

$$
\lim _{n \rightarrow \infty} \sum_{k=1}^{\infty}\left\|I_{k}\left(u_{n}\left(t_{k}\right)\right)-I_{k}\left(\bar{u}\left(t_{k}\right)\right)\right\|=0 \text {. }
$$

It follows from (23), (26), and (29) that $\left\|A u_{n}-A \bar{u}\right\|_{B} \rightarrow 0$ as $n \rightarrow \infty$, and the continuity of $A$ is proved.

Finally, we prove that $A\left(Q_{p q}\right)$ is relatively compact, where $q>p>0$ are arbitrarily given. Let $v_{n} \in A\left(Q_{p q}\right)(n=1,2,3, \ldots)$. Then, by (7),

$$
N^{-1} \beta^{-1}(1-\gamma) p \leq\left\|v_{n}(t)\right\| \leq q, \quad \forall t \in J(n=1,2,3, \ldots) .
$$

Similar to (9), (12), (15), and observing (30), we have

$$
\begin{aligned}
& \left\|f\left(t, v_{n}(t),\left(T v_{n}\right)(t),\left(S v_{n}\right)(t)\right)\right\| \leq M_{1} a(t), \quad \forall t \in J_{+}(n=1,2,3, \ldots), \\
& \left\|I_{k}\left(v_{n}\left(t_{k}\right)\right)\right\| \leq D_{1} \gamma_{k} \quad(k, n=1,2,3, \ldots)
\end{aligned}
$$

and

$$
\left\|A v_{n}\right\|_{B} \leq \frac{\beta+\gamma}{\beta+\gamma-1}\left(M_{1} a^{*}+D_{1} \gamma^{*}\right) \quad(n=1,2,3, \ldots),
$$

where

$$
M_{1}=\max \left\{g(x, y, z): N^{-1} \beta^{-1}(1-\gamma) p \leq x \leq q, 0 \leq y \leq k^{*} q, 0 \leq z \leq h^{*} q\right\}
$$

and

$$
D_{1}=\max \left\{F(x): N^{-1} \beta^{-1}(1-\gamma) p \leq x \leq q\right\} .
$$

Consider $J_{i}=\left(t_{i-1}, t_{i}\right]$ for any fixed $i$. By (6) and (31), we have

$$
\begin{aligned}
\left\|\left(A v_{n}\right)\left(t^{\prime}\right)-\left(A v_{n}\right)(t)\right\| & \leq \int_{t}^{t^{\prime}}\left\|f\left(s, v_{n}(s),\left(T v_{n}\right)(s),\left(S v_{n}\right)(s)\right)\right\| d s \\
& \leq M_{1} \int_{t}^{t^{\prime}} a(s) d s, \quad \forall t, t^{\prime} \in J_{i}, t^{\prime}>t(n=1,2,3, \ldots),
\end{aligned}
$$

which implies that the functions $\left\{w_{n}(t)\right\}(n=1,2,3, \ldots)$ defined by

$$
w_{n}(t)=\left\{\begin{array}{ll}
\left(A v_{n}\right)(t), & \forall t \in J_{i}=\left(t_{i-1}, t_{i}\right], \\
\left(A v_{n}\right)\left(t_{i-1}^{+}\right), & \forall t=t_{i-1}
\end{array} \quad(n=1,2,3, \ldots)\right.
$$


$\left(\left(A u_{n}\right)\left(t_{i-1}^{+}\right)\right.$denotes the right limit of $\left(A u_{n}\right)(t)$ at $\left.t=t_{i-1}\right)$ are equicontinuous on $\bar{J}_{i}=\left[t_{i-1}, t_{i}\right]$. On the other hand, for any $\epsilon>0$, choose a sufficiently large $\tau>\eta$ and a sufficiently large positive integer $j>m$ such that

$$
M_{1} \int_{\tau}^{\infty} a(s) d s<\epsilon, \quad D_{1} \sum_{k=j+1}^{\infty} \gamma_{k}<\epsilon .
$$

We have, by (35), (6), (31), (32), and (36),

$$
\begin{aligned}
w_{n}(t)= & \frac{1}{\beta+\gamma-1}\left\{\int_{\eta}^{\tau} f\left(s, v_{n}(s),\left(T v_{n}\right)(s),\left(S v_{n}\right)(s)\right) d s\right. \\
& +\int_{\tau}^{\infty} f\left(s, v_{n}(s),\left(T v_{n}\right)(s),\left(S v_{n}\right)(s)\right) d s \\
& +(1-\gamma) \int_{0}^{\eta} f\left(s, v_{n}(s),\left(T v_{n}\right)(s),\left(S v_{n}\right)(s)\right) d s+\sum_{k=m}^{j} I_{k}\left(v_{n}\left(t_{k}\right)\right) \\
& \left.+\sum_{k=j+1}^{\infty} I_{k}\left(v_{n}\left(t_{k}\right)\right)+(1-\gamma) \sum_{k=1}^{m-1} I_{k}\left(v_{n}\left(t_{k}\right)\right)\right\}+\int_{0}^{t} f\left(s, v_{n}(s),\left(T v_{n}\right)(s),\left(S v_{n}\right)(s)\right) d s \\
& +\sum_{k=1}^{i-1} I_{k}\left(v_{n}\left(t_{k}\right)\right), \quad \forall t \in \bar{J}_{i}(n=1,2,3, \ldots)
\end{aligned}
$$

and

$$
\begin{aligned}
& \left\|\int_{\tau}^{\infty} f\left(s, v_{n}(s),\left(T v_{n}\right)(s),\left(S v_{n}\right)(s)\right) d s\right\|<\epsilon \quad(n=1,2,3, \ldots), \\
& \left\|\sum_{k=j+1}^{\infty} I_{k}\left(v_{n}\left(t_{k}\right)\right)\right\|<\epsilon \quad(n=1,2,3, \ldots) .
\end{aligned}
$$

It follows from (37), (38), (39), and ([8], Theorem 1.2.3) that

$$
\begin{aligned}
\alpha(W(t)) \leq & \frac{1}{\beta+\gamma-1}\left\{2 \int_{\eta}^{\tau} \alpha(f(s, V(s),(T V)(s),(S V)(s))) d s+2 \epsilon\right. \\
& +2(1-\gamma) \int_{0}^{\eta} \alpha(f(s, V(s),(T V)(s),(S V)(s))) d s+\sum_{k=m}^{j} \alpha\left(I_{k}\left(V\left(t_{k}\right)\right)\right)+2 \epsilon \\
& \left.+(1-\gamma) \sum_{k=1}^{m-1} \alpha\left(I_{k}\left(V\left(t_{k}\right)\right)\right)\right\}+2 \int_{0}^{t} \alpha(f(s, V(s),(T V)(s),(S V)(s))) d s \\
& +\sum_{k=1}^{i-1} \alpha\left(I_{k}\left(V\left(t_{k}\right)\right)\right), \quad \forall t \in \bar{J}_{i},
\end{aligned}
$$

where $W(t)=\left\{w_{n}(t): n=1,2,3, \ldots\right\}, V(s)=\left\{v_{n}(s): n=1,2,3, \ldots\right\},(T V)(s)=\left\{\left(T v_{n}\right)(s): n=\right.$ $1,2,3, \ldots\},(S V)(s)=\left\{\left(S v_{n}\right)(s): n=1,2,3, \ldots\right\}$ and $\alpha(U)$ denotes the Kuratowski measure of noncompactness of bounded set $U \subset E$ (see [8, Section 1.2]). Since $V(s) \subset P_{p^{*} q^{\prime \prime}}$ and 
$(T V)(s),(S V)(s) \subset P_{q^{*}}$ for $s \in J$, where $p^{*}=N^{-1} \beta^{-1}(1-\gamma) p$ and $q^{*}=\max \left\{q, k^{*} q, h^{*} q\right\}$, we see that, by condition $\left(\mathrm{H}_{4}\right)$,

$$
\alpha(f(s, V(s),(T V)(s),(S V)(s)))=0, \quad \forall s \in J
$$

and

$$
\alpha\left(I_{k}\left(V\left(t_{k}\right)\right)\right)=0 \quad(k=1,2,3, \ldots) .
$$

It follows from (40) to (42) that

$$
\alpha(W(t)) \leq \frac{4 \epsilon}{\beta+\gamma-1}, \quad \forall t \in \bar{J}_{i},
$$

which implies by virtue of the arbitrariness of $\epsilon$ that $\alpha(W(t))=0$ for $t \in \bar{J}_{i}$.

By the Ascoli-Arzela theorem (see [8, Theorem 1.2.5]), we conclude that $W=\left\{w_{n}: n=\right.$ $1,2,3, \ldots\}$ is relatively compact in $C\left[\bar{J}_{i}, E\right]$, hence, $\left\{w_{n}(t)\right\}$ has a subsequence which is convergent uniformly on $\bar{J}_{i}$, so, $\left\{\left(A v_{n}\right)(t)\right\}$ has a subsequence which is convergent uniformly on $J_{i}$. Since $i$ may be any positive integer, so, by diagonal method, we can choose a subsequence $\left\{\left(A v_{n_{i}}\right)(t)\right\}$ of $\left\{\left(A v_{n}\right)(t)\right\}$ such that $\left\{\left(A v_{n_{i}}\right)(t)\right\}$ is convergent uniformly on each $J_{k}$ $(k=1,2,3, \ldots)$. Let

$$
\lim _{i \rightarrow \infty}\left(A v_{n_{i}}\right)(t)=w(t), \quad \forall t \in J .
$$

It is clear that $w \in P C[J, P]$. By (33), we have

$$
\left\|A v_{n_{i}}\right\|_{B} \leq \frac{\beta+\gamma}{\beta+\gamma-1}\left(M_{1} a^{\prime \prime}+D_{1} \gamma^{*}\right) \quad(i=1,2,3, \ldots),
$$

which implies that $w \in B P C[, P]$ and

$$
\|w\|_{B} \leq \frac{\beta+\gamma}{\beta+\gamma-1}\left(M_{1} a^{*}+D_{1} \gamma^{*}\right) .
$$

Let $\epsilon>0$ be arbitrarily given and choose a sufficiently large positive number $\tau$ such that

$$
M_{1} \int_{\tau}^{\infty} a(s) d s+D_{1} \sum_{t_{k} \geq \tau} \gamma_{k}<\epsilon
$$

For any $\tau<t<\infty$, we have, by (6),

$$
\begin{aligned}
\left(A v_{n_{i}}\right)(t)-\left(A v_{n_{i}}\right)(\tau)= & \int_{\tau}^{t} f\left(s, v_{n_{i}}(s),\left(T v_{n_{i}}\right)(s),\left(S v_{n_{i}}\right)(s)\right) d s \\
& +\sum_{\tau \leq t_{k}<t} I_{k}\left(v_{n_{i}}(t)\right) \quad(i=1,2,3, \ldots),
\end{aligned}
$$

which implies by virtue of (31), (32), and (43) that

$$
\left\|\left(A v_{n_{i}}\right)(t)-\left(A v_{n_{i}}\right)(\tau)\right\| \leq M_{1} \int_{\tau}^{t} a(s) d s+D_{1} \sum_{\tau \leq t_{k}<t} \gamma_{k}<\epsilon \quad(i=1,2,3, \ldots) .
$$


Letting $i \rightarrow \infty$ in (44), we get

$$
\|w(t)-w(\tau)\| \leq \epsilon, \quad \forall t>\tau .
$$

On the other hand, since $\left\{\left(A v_{n_{i}}\right)(t)\right\}$ converges uniformly to $w(t)$ on $[0, \tau]$ as $i \rightarrow \infty$, there exists a positive integer $i_{0}$ such that

$$
\left\|\left(A v_{n_{i}}\right)(t)-w(t)\right\|<\epsilon, \quad \forall t \in[0, \tau], i>i_{0} .
$$

It follows from (44) to (46) that

$$
\begin{gathered}
\left\|\left(A v_{n_{i}}\right)(t)-w(t)\right\| \leq \\
+\left\|\left(A v_{n_{i}}\right)(t)-\left(A v_{n_{i}}\right)(\tau)\right\|+\left\|\left(A v_{n_{i}}\right)(\tau)-w(\tau)\right\| \\
+\|w(\tau)-w(t)\|<3 \epsilon, \quad \forall t>\tau, i>i_{0} .
\end{gathered}
$$

By (46) and (47), we have

$$
\left\|A v_{n_{i}}-w\right\|_{B} \leq 3 \epsilon, \quad \forall i>i_{0}
$$

hence, $\left\|A v_{n_{i}}-w\right\|_{B} \rightarrow 0$ as $i \rightarrow \infty$, and the relative compactness of $A\left(Q_{p q}\right)$ is proved.

Lemma 2 Let cone $P$ be normal and conditions $\left(\mathrm{H}_{1}\right)-\left(\mathrm{H}_{4}\right)$ be satisfied. Then $u \in Q_{+} \cap$ $C^{1}\left[J_{+}^{\prime}, E\right]$ is a positive solution of the infinite three-point boundary value problem (1) if and only if $u \in Q_{+}$is a solution of the following impulsive integral equation:

$$
\begin{aligned}
u(t)= & \frac{1}{\beta+\gamma-1}\left\{\int_{\eta}^{\infty} f(s, u(s),(T u)(s),(S u)(s)) d s\right. \\
& \left.+(1-\gamma) \int_{0}^{\eta} f(s, u(s),(T u)(s),(S u)(s)) d s+\sum_{k=m}^{\infty} I_{k}\left(u\left(t_{k}\right)\right)+(1-\gamma) \sum_{k=1}^{m-1} I_{k}\left(u\left(t_{k}\right)\right)\right\} \\
& +\int_{0}^{t} f(s, u(s),(T u)(s),(S u)(s)) d s+\sum_{0<t_{k}<t} I_{k}\left(u\left(t_{k}\right)\right), \quad \forall t \in J,
\end{aligned}
$$

i.e., $u$ is a fixed point of operator $A$ defined by (6) in $Q_{+}$.

Proof For $u \in P C[J, E] \cap C^{1}\left[J_{+}^{\prime}, E\right]$, it is easy to get the following formula:

$$
u(t)=u(0)+\int_{0}^{t} u^{\prime}(s) d s+\sum_{0<t_{k}<t}\left[u\left(t_{k}^{+}\right)-u\left(t_{k}\right)\right], \quad \forall t \in J .
$$

Let $u \in Q_{+} \cap C^{1}\left[J_{+}^{\prime}, E\right]$ be a positive solution of the infinite three-point boundary value problem (1). By (1) and (49), we have

$$
u(t)=u(0)+\int_{0}^{t} f(s, u(s),(T u)(s),(S u)(s)) d s+\sum_{0<t_{k}<t} I_{k}\left(u\left(t_{k}\right)\right), \quad \forall t \in J
$$


We have shown in the proof of Lemma 1 that the infinite integral (10) and the infinite series (13) are convergent, so, by taking limits as $t \rightarrow \infty$ in both sides of (50), we get

$$
u(\infty)=u(0)+\int_{0}^{\infty} f(s, u(s),(T u)(s),(S u)(s)) d s+\sum_{k=1}^{\infty} I_{k}\left(u\left(t_{k}\right)\right)
$$

On the other hand, by (1) and (50), we have

$$
u(\infty)=\gamma u(\eta)+\beta u(0)
$$

and

$$
u(\eta)=u(0)+\int_{0}^{\eta} f(s, u(s),(T u)(s),(S u)(s)) d s+\sum_{k=1}^{m-1} I_{k}\left(u\left(t_{k}\right)\right) .
$$

It follows from (51) to (53) that

$$
\begin{aligned}
u(0)= & \frac{1}{\beta+\gamma-1}\left\{\int_{\eta}^{\infty} f(s, u(s),(T u)(s),(S u)(s)) d s\right. \\
& +(1-\gamma) \int_{0}^{\eta} f(s, u(s),(T u)(s),(S u)(s)) d s \\
& \left.+\sum_{k=m}^{\infty} I_{k}\left(u\left(t_{k}\right)\right)+(1-\gamma) \sum_{k=1}^{m-1} I_{k}\left(u\left(t_{k}\right)\right)\right\},
\end{aligned}
$$

and, substituting it into (50), we see that $u(t)$ satisfies equation (48), i.e., $u=A u$.

Conversely, assume that $u \in Q_{+}$is a solution of Equation (48). We have, by (48),

$$
\begin{aligned}
u(0)= & \frac{1}{\beta+\gamma-1}\left\{\int_{\eta}^{\infty} f(s, u(s),(T u)(s),(S u)(s)) d s\right. \\
& +(1-\gamma) \int_{0}^{\eta} f(s, u(s),(T u)(s),(S u)(s)) d s \\
& \left.+\sum_{k=m}^{\infty} I_{k}\left(u\left(t_{k}\right)\right)+(1-\gamma) \sum_{k=1}^{m-1} I_{k}\left(u\left(t_{k}\right)\right)\right\}
\end{aligned}
$$

and

$$
\begin{aligned}
u(\eta)= & \frac{1}{\beta+\gamma-1}\left\{\int_{\eta}^{\infty} f(s, u(s),(T u)(s),(S u)(s)) d s\right. \\
& \left.+(1-\gamma) \int_{0}^{\eta} f(s, u(s),(T u)(s),(S u)(s)) d s+\sum_{k=m}^{\infty} I_{k}\left(u\left(t_{k}\right)\right)+(1-\gamma) \sum_{k=1}^{m-1} I_{k}\left(u\left(t_{k}\right)\right)\right\} \\
& +\int_{0}^{\eta} f(s, u(s),(T u)(s),(S u)(s)) d s+\sum_{k=1}^{m-1} I_{k}\left(u\left(t_{k}\right)\right) .
\end{aligned}
$$


Moreover, by taking limits as $t \rightarrow \infty$ in (48), we see that $u(\infty)$ exists and

$$
\begin{aligned}
u(\infty)= & \frac{1}{\beta+\gamma-1}\left\{\int_{\eta}^{\infty} f(s, u(s),(T u)(s),(S u)(s)) d s\right. \\
& +(1-\gamma) \int_{0}^{\eta} f(s, u(s),(T u)(s),(S u)(s)) d s+\sum_{k=m}^{\infty} I_{k}\left(u\left(t_{k}\right)\right) \\
& \left.+(1-\gamma) \sum_{k=1}^{m-1} I_{k}\left(u\left(t_{k}\right)\right)\right\}+\int_{0}^{\infty} f(s, u(s),(T u)(s),(S u)(s)) d s \\
& +\sum_{k=1}^{\infty} I_{k}\left(u\left(t_{k}\right)\right) .
\end{aligned}
$$

It follows from (54) to (56) that

$$
\gamma u(\eta)+\beta u(0)=u(\infty)
$$

On the other hand, direct differentiation of (48) gives

$$
u^{\prime}(t)=f(t, u(t),(T u)(t),(S u)(t)), \quad \forall t \in J_{+}^{\prime},
$$

and, it is clear, by (48),

$$
\left.\Delta u\right|_{t=t_{k}}=I_{k}\left(u\left(t_{k}\right)\right) \quad(k=1,2,3, \ldots) .
$$

Hence, $u \in C^{1}\left[J_{+}^{\prime}, E\right]$ and $u(t)$ satisfies (1). Since $u \in Q_{+}$, so (7) holds and $\|u\|_{B}>0$, hence $u(t)>\theta$ for $t \in J$. Consequently, $u(t)$ is a positive solution of the infinite three-point boundary value problem (1).

Lemma 3 (The fixed-point theorem of cone expansion and compression with norm type; see [6, Theorem 3] or [7, Theorem 2.3.4]) Let $P$ be a cone in real Banach space $E$ and $\Omega_{1}, \Omega_{2}$ be two bounded open sets in $E$ such that $\theta \in \Omega_{1}, \bar{\Omega}_{1} \subset \Omega_{2}$, and operator A $: P \cap\left(\bar{\Omega}_{2} \backslash \Omega_{1}\right) \rightarrow P$ be completely continuous, where $\theta$ denotes the zero element of $E$ and $\bar{\Omega}_{i}$ denotes the closure of $\Omega_{i}(i=1,2)$. Suppose that one of the following two conditions is satisfied:

(a) $\quad\|A x\| \leq\|x\|, \quad \forall x \in P \cap \partial \Omega_{1} ; \quad\|A x\| \geq\|x\|, \quad \forall x \in P \cap \partial \Omega_{2}$, where $\partial \Omega_{i}$ denotes the boundary of $\Omega_{i}(i=1,2)$.

(b) $\quad\|A x\| \geq\|x\|, \quad \forall x \in P \cap \partial \Omega_{1} ; \quad\|A x\| \leq\|x\|, \quad \forall x \in P \cap \partial \Omega_{2}$.

Then $A$ has at least one fixed point in $P \cap\left(\bar{\Omega}_{2} \backslash \Omega_{1}\right)$.

Remark 1 Lemma 3 is different from the Krasnoselskii fixed-point theorem of cone expansion and compression (see [9, Theorem 44.1]). In Krasnoselskii's theorem, the condition corresponding to (a) is

$$
\text { (a') } \quad A x \nsupseteq x, \quad \forall x \in P \cap \partial \Omega_{1}, \quad A x \not \leq x, \quad \forall x \in P \cap \partial \Omega_{2} .
$$


It is clear, conditions (a) and $\left(a^{\prime}\right)$ are independent each other. On the other hand, in Krasnoselskii's theorem, $\Omega_{1}$ and $\Omega_{2}$ are balls with center $\theta$.

\section{Main theorems}

Let us list more conditions.

$\left(\mathrm{H}_{5}\right)$ There exist $u_{0} \in P_{+}, b \in C\left[U_{+}, R_{++}\right]$and $\tau \in C\left[P_{+}, R_{+}\right]$such that

$$
f(t, u, v, w) \geq b(t) \tau(u) u_{0}, \quad \forall t \in J_{+}, u \in P_{+}, v, w \in P,
$$

and

$$
\frac{\tau(u)}{\|u\|} \rightarrow \infty \text { as } u \in P_{+},\|u\| \rightarrow \infty,
$$

and

$$
b^{*}=\int_{0}^{\infty} b(t) d t<\infty
$$

Remark 2 Condition $\left(\mathrm{H}_{5}\right)$ means that $f(t, u, v, w)$ is superlinear with respect to $u$.

$\left(\mathrm{H}_{6}\right)$ There exist $u_{1} \in P_{+}, c \in C\left[J_{+}, R_{++}\right]$and $\sigma \in C\left[P_{+}, R_{+}\right]$such that

$$
f(t, u, v, w) \geq c(t) \sigma(u) u_{1}, \quad \forall t \in J_{+}, u \in P_{+}, v, w \in P,
$$

and

$$
\sigma(u) \rightarrow \infty \quad \text { as } u \in P_{+},\|u\| \rightarrow 0,
$$

and

$$
c^{*}=\int_{0}^{\infty} c(t) d t<\infty
$$

Theorem 1 Let cone $P$ be normal and conditions $\left(\mathrm{H}_{1}\right)-\left(\mathrm{H}_{6}\right)$ be satisfied. Assume that there exists $a \xi>0$ such that

$$
\frac{N(\beta+\gamma)}{\beta+\gamma-1}\left(M_{\xi} a^{*}+D_{\xi} \gamma^{*}\right)<\xi
$$

where $N$ denotes the normal constant of $P$, and

$$
\begin{aligned}
& M_{\xi}=\max \left\{g(x, y, z): N^{-1} \beta^{-1}(1-\gamma) \xi \leq x \leq \xi, 0 \leq y \leq k^{*} \xi, 0 \leq z \leq h^{*} \xi\right\}, \\
& D_{\xi}=\max \left\{F(x): N^{-1} \beta^{-1}(1-\gamma) \xi \leq x \leq \xi\right\}
\end{aligned}
$$

(for $g(x, y, z), F(x), a^{\prime \prime}$ and $\gamma^{*}$; see conditions $\left(\mathrm{H}_{2}\right)$ and $\left.\left(\mathrm{H}_{3}\right)\right)$. Then the infinite three-point boundary value problem (1) has at least two positive solutions $\left.u^{*}, u^{* *} \in Q_{+} \cap C^{1} J_{+}^{\prime}, E\right]$ such that $0<\left\|u^{*}\right\|_{B}<\xi<\left\|u^{* *}\right\|_{B}$. 
Proof By Lemma 1 and Lemma 2, operator $A$ defined by (6) is continuous from $Q_{+}$into $Q$ and we need to prove that $A$ has two fixed points $u^{*}$ and $u^{* *}$ in $Q_{+}$such that $0<\left\|u^{*}\right\|_{B}<$ $\xi<\left\|u^{* * *}\right\|_{B}$.

By condition $\left(\mathrm{H}_{5}\right)$, there exists a $r_{1}>0$ such that

$$
\tau(u) \geq \frac{\beta(\beta+\gamma-1) N^{2}}{(1-\gamma)^{2} b^{*}\left\|u_{0}\right\|}\|u\|, \quad \forall u \in P_{+},\|u\| \geq r_{1},
$$

so,

$$
f(t, u, v, w) \geq \frac{\beta(\beta+\gamma-1) N^{2}\|u\|}{(1-\gamma)^{2} b^{*}\left\|u_{0}\right\|} b(t) u_{0}, \quad \forall t \in J_{+}, u \in P_{+}, v, w \in P,\|u\| \geq r_{1} .
$$

Choose

$$
r_{2}>\max \left\{N \beta(1-\gamma)^{-1} r_{1}, \xi\right\}
$$

For $u \in Q,\|u\|_{B}=r_{2}$, we have by (7) and (62),

$$
\|u(t)\| \geq N^{-1} \beta^{-1}(1-\gamma)\|u\|_{B}=N^{-1} \beta^{-1}(1-\gamma) r_{2}>r_{1}, \quad \forall t \in J,
$$

so, (6), (63), (61), and (7) imply

$$
\begin{aligned}
(A u)(t) & \geq \frac{1-\gamma}{\beta+\gamma-1}\left(\int_{0}^{\infty} f(s, u(s),(T u)(s),(S u)(s)) d s\right) \\
& \geq \frac{\beta N^{2}}{(1-\gamma) b^{*}\left\|u_{0}\right\|}\left(\int_{0}^{\infty}\|u(s)\| b(s) d s\right) u_{0} \\
& \geq \frac{N\|u\|_{B}}{b^{*}\left\|u_{0}\right\|}\left(\int_{0}^{\infty} b(s) d s\right) u_{0}=\frac{N\|u\|_{B}}{\left\|u_{0}\right\|} u_{0}, \quad \forall t \in J,
\end{aligned}
$$

and consequently,

$$
\|A u\|_{B} \geq\|u\|_{B}, \quad \forall u \in Q,\|u\|_{B}=r_{2} .
$$

By condition $\left(\mathrm{H}_{6}\right)$, there exists $r_{3}>0$ such that

$$
\sigma(u) \geq \frac{(\beta+\gamma-1) N \xi}{(1-\gamma) c^{*}\left\|u_{1}\right\|}, \quad \forall u \in P_{+}, 0<\|u\|<r_{3}
$$

so,

$$
f(t, u, v, w) \geq \frac{(\beta+\gamma-1) N \xi}{(1-\gamma) c^{*}\left\|u_{1}\right\|} c(t) u_{1}, \quad \forall t \in J_{+}, u \in P_{+}, v, w \in P, 0<\|u\|<r_{3} .
$$

Choose

$0<r_{4}<\min \left\{r_{3}, \xi\right\}$

For $u \in Q,\|u\|_{B}=r_{4}$, we have by (68) and (7),

$$
r_{3}>\|u(t)\| \geq N^{-1} \beta^{-1}(1-\gamma)\|u\|_{B}=N^{-1} \beta^{-1}(1-\gamma) r_{4}>0,
$$


so, we get by (6), (69), and (67),

$$
\begin{aligned}
(A u)(t) & \geq \frac{1-\gamma}{\beta+\gamma-1}\left(\int_{0}^{\infty} f(s, u(s),(T u)(s),(S u)(s)) d s\right) \\
& \geq \frac{N \xi}{c^{*}\left\|u_{1}\right\|}\left(\int_{0}^{\infty} c(s) d s\right) u_{1}=\frac{N \xi}{\left\|u_{1}\right\|} u_{1}, \quad \forall t \in J,
\end{aligned}
$$

which implies

$$
\|(A u)(t)\| \geq \xi>r_{4}, \quad \forall t \in J,
$$

and consequently,

$$
\|A u\|_{B}>\|u\|_{B}, \quad \forall u \in Q,\|u\|_{B}=r_{4} .
$$

On the other hand, for $u \in Q,\|u\|_{B}=\xi$, by condition $\left(\mathrm{H}_{2}\right)$, condition $\left(\mathrm{H}_{3}\right)$, (58), and (59), we have

$$
\|f(t, u(t),(T u)(t),(S u)(t))\| \leq M_{\xi} a(t), \quad \forall t \in J_{+}
$$

and

$$
\left\|I_{k}\left(u\left(t_{k}\right)\right)\right\| \leq D_{\xi} \gamma_{k} \quad(k=1,2,3, \ldots) .
$$

It is clear, by (17),

$$
(A u)(t) \leq \frac{\beta+\gamma}{\beta+\gamma-1}\left(\int_{0}^{\infty} f(s, u(s),(T u)(s),(S u)(s)) d s+\sum_{k=1}^{\infty} I_{k}\left(u\left(t_{k}\right)\right)\right), \quad \forall t \in J .
$$

It follows from (71) to (73) that

$$
\|A u\|_{B} \leq \frac{N(\beta+\gamma)}{\beta+\gamma-1}\left(M_{\xi} a^{*}+D_{\xi} \gamma^{*}\right)
$$

Thus, (74) and (57) imply

$$
\|A u\|_{B}<\|u\|_{B}, \quad \forall u \in Q,\|u\|_{B}=\xi .
$$

From (62) and (68), we know $0<r_{4}<\xi<r_{2}$, and by Lemma 1, $A: Q_{r_{4} r_{2}} \rightarrow Q$ is completely continuous, where $Q_{r_{4} r_{2}}=\left\{u \in Q: r_{4} \leq\|u\|_{B} \leq r_{2}\right\}$, hence, (65), (70), (75), and Lemma 3 imply that $A$ has two fixed points $u^{*}, u^{* * *} \in Q_{+}$such that $r_{4}<\left\|u^{*}\right\|_{B}<\xi<\left\|u^{* * *}\right\|_{B} \leq r_{2}$. The proof is complete.

Theorem 2 Let cone P be normal and conditions $\left(\mathrm{H}_{1}\right)-\left(\mathrm{H}_{4}\right)$ and $\left(\mathrm{H}_{6}\right)$ be satisfied. Assume that

$$
\frac{g(x, y, z)}{x+y+z} \rightarrow 0 \quad \text { as } x \rightarrow \infty
$$


uniformly for $y, z \in R_{+}$, and

$$
\frac{F(x)}{x} \rightarrow 0 \quad \text { as } x \rightarrow \infty
$$

$\left(\right.$ for $g(x, y, z)$ and $F(x)$, see conditions $\left(\mathrm{H}_{2}\right)$ and $\left.\left(\mathrm{H}_{3}\right)\right)$. Then the infinite three-point boundary value problem (1) has at least one positive solution $\left.u^{\prime \prime} \in Q_{+} \cap C^{1} J_{+}^{\prime}, E\right]$.

Proof As in the proof of Theorem 1, we can choose $r_{4}>0$ such that (70) holds (in this case, we put $\xi=1$ in (66) and (68)). On the other hand, by (76) and (77), there exists $r_{5}>0$ such that

$$
g(x, y, z) \leq \epsilon_{0}(x+y+z), \quad \forall x>r_{5}, y \geq 0, z \geq 0
$$

and

$$
F(x) \leq \epsilon_{0} x, \quad \forall x>r_{5}
$$

where

$$
\epsilon_{0}=\frac{\beta+\gamma-1}{N(\beta+\gamma)\left[\left(1+k^{*}+h^{*}\right) a^{*}+\gamma^{*}\right]} .
$$

Choose

$$
r_{6}>\max \left\{N \beta(1-\gamma)^{-1} r_{5}, r_{4}\right\}
$$

For $u \in Q,\|u\|_{B}=r_{6}$, we have by (7) and (81),

$$
\|u(t)\| \geq N^{-1} \beta^{-1}(1-\gamma) r_{6}>r_{5}, \quad \forall t \in J
$$

so, (78) and (79) imply

$$
\begin{aligned}
g(\|u(t)\|,\|(T u)(t)\|,\|(S u)(t)\|) & \leq \epsilon_{0}(\|u(t)\|+\|(T u)(t)\|+\|(S u)(t)\|) \\
& \leq \epsilon_{0}\left(1+k^{*}+h^{*}\right) r_{6}, \quad \forall t \in J
\end{aligned}
$$

and

$$
F\left(\left\|u\left(t_{k}\right)\right\|\right) \leq \epsilon_{0}\left\|u\left(t_{k}\right)\right\| \leq \epsilon_{0} r_{6} \quad(k=1,2,3, \ldots)
$$

It follows from (73), conditions $\left(\mathrm{H}_{2}\right)$, condition $\left(\mathrm{H}_{3}\right),(82),(83)$, and (80) that

$$
\begin{aligned}
\|(A u)(t)\| & \leq \frac{N(\beta+\gamma)}{\beta+\gamma-1}\left\{\epsilon_{0}\left(1+k^{*}+h^{*}\right) r_{6} \int_{0}^{\infty} a(s) d s+\epsilon_{0} r_{6} \sum_{k=1}^{\infty} \gamma_{k}\right\} \\
& =\frac{N(\beta+\gamma) \epsilon_{0} r_{6}}{\beta+\gamma-1}\left\{\left(1+k^{*}+h^{*}\right) a^{*}+\gamma^{*}\right\}=r_{6}, \quad \forall t \in J,
\end{aligned}
$$


and consequently,

$$
\|A u\|_{B} \leq\|u\|_{B}, \quad \forall u \in Q,\|u\|_{B}=r_{6} .
$$

Since $r_{6}>r_{4}$ by virtue of (81), we conclude from (70), (84), and Lemma 3 that $A$ has a fixed point $u^{*} \in Q_{+}$such that $r_{4}<\left\|u^{*}\right\|_{B} \leq r_{6}$. The theorem is proved.

Example 1 Consider the infinite system of scalar first-order impulsive singular integrodifferential equations of mixed type on the half line:

$$
\left\{\begin{aligned}
& u_{n}^{\prime}(t)= \frac{e^{-2 t}}{20 n^{2} \sqrt{t}}\left\{\frac{1}{8}\left(u_{n+1}(t)+\sum_{m=1}^{\infty} u_{m}(t)\right)^{2}+\frac{1}{9}\left(\sum_{m=1}^{\infty} u_{m}(t)\right)^{-1}\right\} \\
&+\frac{e^{-3 t}}{18 n^{3} \sqrt{t}}\left\{\left(\int_{0}^{t} e^{-(t+1) s} u_{n}(s) d s\right)^{2}+\frac{1}{2}\left(\int_{0}^{\infty} \frac{u_{n+2}(s) d s}{(1+t+s)^{2}}\right)^{3}\right\}, \\
& \forall 0< t<\infty, t \neq k(k=1,2,3, \ldots ; n=1,2,3, \ldots), \\
&\left.\Delta u_{n}\right|_{t=k}=\frac{5^{-k}}{16 n^{2}}\left\{u_{2 n}(k)+\frac{1}{3}\left(\sum_{m=1}^{\infty} u_{m}(k)\right)^{-\frac{1}{2}}\right\} \quad(k=1,2,3, \ldots ; n=1,2,3, \ldots), \\
& u_{n}(\infty)=\frac{1}{2} u_{n}\left(\frac{9}{2}\right)+6 u_{n}(0) \quad(n=1,2,3, \ldots) .
\end{aligned}\right.
$$

Conclusion Infinite system (85) has at least two positive solutions $\left\{u_{n}^{*}(t)\right\}(n=1,2,3, \ldots)$ and $\left\{u_{n}^{* * *}(t)\right\}(n=1,2,3, \ldots)$ such that

$$
\begin{aligned}
& 0<\inf _{0 \leq t<\infty} \sum_{n=1}^{\infty} u_{n}^{*}(t) \leq \sup _{0 \leq t<\infty} \sum_{n=1}^{\infty} u_{n}^{*}(t)<1<\sup _{0 \leq t<\infty} \sum_{n=1}^{\infty} u_{n}^{* * *}(t), \\
& \inf _{0 \leq t<\infty} \sum_{n=1}^{\infty} u_{n}^{* * * *}(t)>0 .
\end{aligned}
$$

Proof Let $E=l^{1}=\left\{u=\left(u_{1}, \ldots, u_{n}, \ldots\right): \sum_{n=1}^{\infty}\left|u_{n}\right|<\infty\right\}$ with norm $\|u\|=\sum_{n=1}^{\infty}\left|u_{n}\right|$ and $P=\left\{\left(u_{1}, \ldots, u_{n}, \ldots\right): u_{n} \geq 0, n=1,2,3, \ldots\right\}$. Then $P$ is a normal cone in $E$ with normal constant $N=1$, and infinite system (85) can be regarded as an infinite three-point boundary value problem of form (1). In this situation, $u=\left(u_{1}, \ldots, u_{n}, \ldots\right), v=\left(v_{1}, \ldots, v_{n}, \ldots\right)$, $w=\left(w_{1}, \ldots, w_{n}, \ldots\right), t_{k}=k(k=1,2,3, \ldots), K(t, s)=e^{-(t+1) s}, H(t, s)=(1+t+s)^{-2}, \eta=\frac{9}{2}, \gamma=\frac{1}{2}$, $\beta=6, f=\left(f_{1}, \ldots, f_{n}, \ldots\right)$ and $I_{k}=\left(I_{k 1}, \ldots, I_{k n}, \ldots\right)$, in which

$$
\begin{aligned}
& f_{n}(t, u, v, w) \\
& \quad=\frac{e^{-2 t}}{20 n^{2} \sqrt{t}}\left\{\frac{1}{8}\left(u_{n+1}+\sum_{m=1}^{\infty} u_{m}\right)^{2}+\frac{1}{9}\left(\sum_{m=1}^{\infty} u_{m}\right)^{-1}\right\}+\frac{e^{-3 t}}{18 n^{3} \sqrt{t}}\left(v_{n}^{2}+\frac{1}{2} w_{n+2}^{3}\right), \\
& \forall t \in J_{+}=(0, \infty), u \in P_{+}=\{u \in P:\|u\|>0\}, v, w \in P(n=1,2,3, \ldots)
\end{aligned}
$$

and

$$
I_{k n}(u)=\frac{5^{-k}}{16 n^{2}}\left\{u_{2 n}+\frac{1}{3}\left(\sum_{m=1}^{\infty} u_{m}\right)^{-\frac{1}{2}}\right\}, \quad \forall u \in P_{+}(k=1,2,3, \ldots ; n=1,2,3, \ldots)
$$


It is easy to see that $f \in C\left[U_{+} \times P_{+} \times P \times P, P\right], I_{k} \in C\left[P_{+}, P\right](k=1,2,3, \ldots)$ and condition $\left(\mathrm{H}_{1}\right)$ is satisfied and $k^{*} \leq 1, h^{*} \leq 1$. We have, by (86),

$$
\begin{aligned}
0 \leq & f_{n}(t, u, v, w) \leq \frac{e^{-2 t}}{20 n^{2} \sqrt{t}}\left\{\frac{1}{8}(2\|u\|)^{2}+\frac{1}{9}\|u\|^{-1}\right\}+\frac{e^{-3 t}}{18 n^{3} \sqrt{t}}\left(\|v\|^{2}+\frac{1}{2}\|w\|^{3}\right) \\
\leq & \frac{e^{-2 t}}{n^{2} \sqrt{t}}\left(\frac{1}{40}\|u\|^{2}+\frac{1}{180}\|u\|^{-1}+\frac{1}{18}\|v\|^{2}+\frac{1}{36}\|w\|^{3}\right), \\
& \forall t \in J_{+}, u \in P_{+}, v, w \in P(n=1,2,3, \ldots),
\end{aligned}
$$

so, observing the inequality $\sum_{n=1}^{\infty} \frac{1}{n^{2}}<2$, we get

$$
\begin{aligned}
& \|f(t, u, v, w)\|=\sum_{n=1}^{\infty} f_{n}(t, u, v, w) \leq \frac{e^{-2 t}}{\sqrt{t}}\left(\frac{1}{20}\|u\|^{2}+\frac{1}{90}\|u\|^{-1}+\frac{1}{9}\|v\|^{2}+\frac{1}{18}\|w\|^{3}\right), \\
& \forall t \in J_{+}, u \in P_{+}, v, w \in P
\end{aligned}
$$

which implies that condition $\left(\mathrm{H}_{2}\right)$ is satisfied for

$$
a(t)=\frac{e^{-2 t}}{\sqrt{t}}
$$

and

$$
g(x, y, z)=\frac{1}{20} x^{2}+\frac{1}{90 x}+\frac{1}{9} y^{2}+\frac{1}{18} z^{3}
$$

with

$$
a^{\prime \prime}=\int_{0}^{\infty} \frac{e^{-2 t}}{\sqrt{t}} d t<\int_{0}^{1} \frac{d t}{\sqrt{t}}+\int_{1}^{\infty} e^{-2 t} d t=2+\frac{1}{2} e^{-2}<\frac{29}{14} .
$$

By (87), we have

$$
0 \leq I_{k n}(u) \leq \frac{5^{-k}}{16 n^{2}}\left(\|u\|+\frac{1}{3}\|u\|^{-\frac{1}{2}}\right), \quad \forall u \in P_{+}(k=1,2,3, \ldots ; n=1,2,3, \ldots),
$$

so,

$$
\left\|I_{k}(u)\right\| \leq \frac{1}{8} 5^{-k}\left(\|u\|+\frac{1}{3}\|u\|^{-\frac{1}{2}}\right), \quad \forall u \in P_{+}(k=1,2,3, \ldots),
$$

which implies that condition $\left(\mathrm{H}_{3}\right)$ is satisfied for $\gamma_{k}=\frac{1}{8} 5^{-k}\left(\gamma^{*}=\frac{1}{32}\right)$ and

$$
F(x)=x+\frac{1}{3 \sqrt{x}}
$$

On the other hand, (86) implies

$$
f_{n}(t, u, v, w) \geq \frac{e^{-2 t}}{160 n^{2} \sqrt{t}}\|u\|^{2}, \quad \forall t \in J_{+}, u \in P_{+}, v, w \in P(n=1,2,3, \ldots)
$$


and

$$
f_{n}(t, u, v, w) \geq \frac{e^{-2 t}}{180 n^{2} \sqrt{t}}\|u\|^{-1}, \quad \forall t \in J_{+}, u \in P_{+}, v, w \in P(n=1,2,3, \ldots),
$$

so, we see that condition $\left(\mathrm{H}_{5}\right)$ is satisfied for $b(t)=\frac{e^{-2 t}}{160 \sqrt{t}}\left(b^{*}<\frac{29}{2,240}\right), \tau(u)=\|u\|^{2}$ and $u_{0}=$ $\left(1, \ldots, \frac{1}{n^{2}}, \ldots\right)$ and condition $\left(\mathrm{H}_{6}\right)$ is satisfied for $c(t)=\frac{e^{-2 t}}{180 \sqrt{t}}\left(c^{*}<\frac{29}{2,520}\right), \sigma(u)=\|u\|^{-1}$ and $u_{1}=\left(1, \ldots, \frac{1}{n^{2}}, \ldots\right)$. In addition, from $(90)$, we have

$$
\|f(t, u, v, w)\| \geq\left(\sum_{n=1}^{\infty} \frac{1}{n^{2}}\right) \frac{e^{-2 t}}{160 \sqrt{t}}\|u\|^{-1}>\frac{e^{-2 t}}{160 \sqrt{t}}\|u\|^{-1}, \quad \forall t \in J_{+}, u \in P_{+}, v, w \in P,
$$

which implies that (3) and (4) hold, i.e., $f(t, u, v, w)$ is singular at $t=0$ and $u=\theta$. Moreover, from (87), we get

$$
I_{k n}(u) \geq \frac{5^{-k}}{48 n^{2}}\|u\|^{-\frac{1}{2}}, \quad \forall u \in P_{+}(k=1,2,3, \ldots ; n=1,2,3, \ldots),
$$

and so,

$$
\left\|I_{k}(u)\right\| \geq\left(\sum_{n=1}^{\infty} \frac{1}{n^{2}}\right) \frac{5^{-k}}{48}\|u\|^{-\frac{1}{2}}>\frac{5^{-k}}{48}\|u\|^{-\frac{1}{2}}, \quad \forall u \in P_{+}(k=1,2,3, \ldots),
$$

which implies that (5) holds, i.e., $I_{k}(u)(k=1,2,3, \ldots)$ are singular at $u=\theta$. Now, we check that condition $\left(\mathrm{H}_{4}\right)$ is satisfied. Let $t \in J_{+}$and $r>p>0$ be fixed, and $\left\{z^{(m)}\right\}$ be any sequence in $f\left(t, P_{p r}, P_{r}, P_{r}\right)$, where $z^{(m)}=\left(z_{1}^{(m)}, \ldots, z_{n}^{(m)}, \ldots\right)$. Then, we have, by (86) and (88),

$$
0 \leq z_{n}^{(m)} \leq \frac{e^{-2 t}}{n^{2} \sqrt{t}}\left(\frac{29}{360} r^{2}+\frac{1}{180 p}+\frac{1}{36} r^{3}\right) \quad(n, m=1,2,3, \ldots) .
$$

So, $\left\{z_{n}^{(m)}\right\}$ is bounded, and, by diagonal method, we can choose a subsequence $\left\{m_{i}\right\} \subset\{m\}$ such that

$$
z_{n}^{\left(m_{i}\right)} \rightarrow \bar{z}_{n} \quad \text { as } i \rightarrow \infty(n=1,2,3, \ldots)
$$

which implies by virtue of (91) that

$$
0 \leq \bar{z}_{n} \leq \frac{e^{-2 t}}{n^{2} \sqrt{t}}\left(\frac{29}{360} r^{2}+\frac{1}{180 p}+\frac{1}{36} r^{3}\right) \quad(n=1,2,3, \ldots) .
$$

Consequently, $\bar{z}=\left(\bar{z}_{1}, \ldots, \bar{z}_{n}, \ldots\right) \in l^{1}=E$. Let $\epsilon>0$ be given. Choose a positive integer $n_{0}$ such that

$$
\frac{e^{-2 t}}{\sqrt{t}}\left(\sum_{n=n_{0}+1}^{\infty} \frac{1}{n^{2}}\right)\left(\frac{29}{360} r^{2}+\frac{1}{180 p}+\frac{1}{36} r^{3}\right)<\frac{\epsilon}{3} .
$$

By (92), we see that there exists a positive integer $i_{0}$ such that

$$
\left|z_{n}^{\left(m_{i}\right)}-\bar{z}_{n}\right|<\frac{\epsilon}{3 n_{0}}, \quad \forall i>i_{0}\left(n=1,2, \ldots, n_{0}\right) .
$$


It follows from (91) to (95) that

$$
\begin{aligned}
\left\|z^{\left(m_{i}\right)}-\bar{z}\right\|= & \sum_{n=1}^{\infty}\left|z_{n}^{\left(m_{i}\right)}-\bar{z}_{n}\right| \leq \sum_{n=1}^{n_{0}}\left|z_{n}^{\left(m_{i}\right)}-\bar{z}_{n}\right|+\sum_{n=n_{0}+1}^{\infty}\left|z_{n}^{\left(m_{i}\right)}\right| \\
& +\sum_{n=n_{0}+1}^{\infty}\left|\bar{z}_{n}\right|<\frac{\epsilon}{3}+\frac{\epsilon}{3}+\frac{\epsilon}{3}=\epsilon, \quad \forall i>i_{0},
\end{aligned}
$$

hence, $z^{\left(m_{i}\right)} \rightarrow \bar{z}$ in $E$ as $i \rightarrow \infty$. Thus, we have proved that $f\left(t, P_{p r}, P_{r}, P_{r}\right)$ is relatively compact in $E$. Similarly, by using (89), we can prove that $I_{k}\left(P_{p r}\right)$ is relatively compact in $E$. Hence, condition $\left(\mathrm{H}_{4}\right)$ is satisfied. Finally, we check that inequality (57) is satisfied for $\xi=1$. In this case,

$$
M_{1} \leq \max \left\{g(x, y, z): \frac{1}{12} \leq x \leq 1,0 \leq y \leq 1,0 \leq z \leq 1\right\} \leq \frac{1}{20}+\frac{12}{90}+\frac{1}{9}+\frac{1}{18}=\frac{7}{20}
$$

and

$$
D_{1}=\max \left\{F(x): \frac{1}{12} \leq x \leq 1\right\} \leq 1+\frac{2 \sqrt{3}}{3}<2.2,
$$

so,

$$
\frac{N(\beta+\gamma)}{\beta+\gamma-1}\left(M_{1} a^{*}+D_{1} \gamma^{*}\right)<\frac{13}{11}\left(\frac{7}{20} \times \frac{29}{14}+2.2 \times \frac{1}{32}\right)=\frac{1,651}{1,760}<1,
$$

i.e., inequality (57) is satisfied for $\xi=1$. Hence, our conclusion follows from Theorem 1 .

Example 2 Consider the infinite system of scalar first order impulsive singular integrodifferential equations of mixed type on the half line:

$$
\left\{\begin{aligned}
& u_{n}^{\prime}(t)= \frac{1}{n^{3} t^{\frac{1}{3}}(1+t)^{3}}\left\{\sqrt{u_{n}(t)+2 u_{n+1}(t)}+\left(\sum_{m=1}^{\infty} u_{m}(t)\right)^{-2}\right\} \\
& \quad+\frac{1}{n^{4} t^{\frac{1}{3}}(1+t)^{4}}\left\{\left(\int_{0}^{t} \frac{u_{2 n}(s) d s}{1+t s+s^{2}}\right)^{\frac{1}{2}}+\left(\int_{0}^{\infty} e^{-s} \sin ^{2}(t-s) u_{3 n}(s) d s\right)^{\frac{1}{3}}\right\} \\
& \forall 0 \leq t<\infty, t \neq 2 k(k=1,2,3, \ldots ; n=1,2,3, \ldots) ; \\
&\left.\Delta u_{n}\right|_{t=2 k}=\frac{e^{-k}}{n^{2}}\left(u_{2 n+1}(2 k)\right)^{\frac{1}{3}}+\frac{2^{-k}}{n^{3}}\left(\sum_{m=1}^{\infty} u_{m}(2 k)\right)^{-3} \\
& \quad(k=1,2,3, \ldots ; n=1,2,3, \ldots), \\
& 4 u_{n}(\infty)=3 u_{n}(7)+2 u_{n}(0) \quad(n=1,2,3, \ldots) .
\end{aligned}\right.
$$

Conclusion Infinite system (96) has at least one positive solution $\left\{u_{n}^{*}(t)\right\}(n=1,2,3, \ldots)$ such that

$$
\inf _{0 \leq t<\infty} \sum_{n=1}^{\infty} u_{n}^{*}(t)>0
$$

Proof Let $E=l^{1}=\left\{u=\left(u_{1}, \ldots, u_{n}, \ldots\right): \sum_{n=1}^{\infty}\left|u_{n}\right|<\infty\right\}$ with norm $\|u\|=\sum_{n=1}^{\infty}\left|u_{n}\right|$ and $P=$ $\left\{u=\left(u_{1}, \ldots, u_{n}, \ldots\right) \in l^{1}: u_{n} \geq 0, n=1,2,3, \ldots\right\}$. Then $P$ is a normal cone in $E$ with normal constant $N=1$, and infinite system (96) can be regarded as an infinite three-point boundary value problem of form (1) in $E$. In this situation, $u=\left(u_{1}, \ldots, u_{n}, \ldots\right), v=\left(v_{1}, \ldots, v_{n}, \ldots\right)$, 


$$
\begin{aligned}
& w=\left(w_{1}, \ldots, w_{n}, \ldots\right), t_{k}=2 k(k=1,2,3, \ldots), K(t, s)=\left(1+t s+s^{2}\right)^{-1}, H(t, s)=e^{-s} \sin ^{2}(t-s), \\
& \eta=7, \gamma=\frac{3}{4}, \beta=\frac{1}{2}, f=\left(f_{1}, \ldots, f_{n}, \ldots\right) \text { and } I_{k}=\left(I_{k 1}, \ldots, I_{k n}, \ldots\right) \text {, in which } \\
& f_{n}(t, u, v, w)=\frac{1}{n^{3} t^{\frac{1}{3}}(1+t)^{3}}\left\{\sqrt{u_{n}+2 u_{n+1}}+\left(\sum_{m=1}^{\infty} u_{m}\right)^{-2}\right\}+\frac{1}{n^{4} t^{\frac{1}{3}}(1+t)^{4}}\left(v_{2 n}^{\frac{1}{2}}+w_{3 n}^{\frac{1}{3}}\right), \\
& \forall t \in J_{+}, u \in P_{+}, v, w \in P(n=1,2,3, \ldots)
\end{aligned}
$$

and

$$
I_{k n}(u)=\frac{e^{-k}}{n^{2}} u_{2 n+1}^{\frac{1}{3}}+\frac{2^{-k}}{n^{3}}\left(\sum_{m=1}^{\infty} u_{m}\right)^{-3} \quad(k=1,2,3, \ldots ; n=1,2,3, \ldots) .
$$

It is clear that $f \in C\left[J_{+} \times P_{+} \times P \times P, P\right], I_{k} \in C\left[P_{+}, P\right](k=1,2,3, \ldots)$ and condition $\left(\mathrm{H}_{1}\right)$ is satisfied and $k^{\prime \prime} \leq \frac{\pi}{2}, h^{*} \leq 1$. We have, by (97) and (98),

$$
\begin{gathered}
0 \leq f_{n}(t, u, v, w) \leq \frac{1}{n^{3} t^{\frac{1}{3}}(1+t)^{3}}\left(\sqrt{3\|u\|}+\|u\|^{-2}+\|v\|^{\frac{1}{2}}+\|w\|^{\frac{1}{3}}\right), \\
\forall t \in J_{+}, u \in P_{+}, v, w \in P(n=1,2,3, \ldots)
\end{gathered}
$$

and

$$
0 \leq I_{k n}(u) \leq \frac{2^{-k}}{n^{2}}\left(\|u\|^{\frac{1}{3}}+\|u\|^{-3}\right), \quad \forall u \in P_{+}(k=1,2,3, \ldots ; n=1,2,3, \ldots),
$$

so, observing

$$
\sum_{n=1}^{\infty} \frac{1}{n^{3}}<\sum_{n=1}^{\infty} \frac{1}{n^{2}}<2
$$

we get

$$
\begin{aligned}
& \|f(t, u, v, w)\| \leq \frac{1}{t^{\frac{1}{3}}(1+t)^{3}}\left(2 \sqrt{3} \sqrt{\|u\|}+2\|u\|^{-2}+2\|v\|^{\frac{1}{2}}+2\|w\|^{\frac{1}{3}}\right), \\
& \forall t \in J_{+}, u \in P_{+}, v, w \in P
\end{aligned}
$$

and

$$
\left\|I_{k}(u)\right\| \leq 2^{-k+1}\left(\|u\|^{\frac{1}{3}}+\|u\|^{-3}\right), \quad \forall u \in P_{+}(k=1,2,3, \ldots),
$$

which imply that conditions $\left(\mathrm{H}_{2}\right)$ is satisfied for

$$
a(t)=\frac{1}{t^{\frac{1}{3}}(1+t)^{3}}
$$

and

$$
g(x, y, z)=2 \sqrt{3} \sqrt{x}+2 x^{-2}+2 y^{\frac{1}{2}}+2 z^{\frac{1}{3}}
$$


with

$$
a^{*}=\int_{0}^{\infty} \frac{d t}{t^{\frac{1}{3}}(1+t)^{3}}<\int_{0}^{1} \frac{d t}{t^{\frac{1}{3}}}+\int_{1}^{\infty} \frac{d t}{(1+t)^{3}}=\frac{13}{8}
$$

and $\left(\mathrm{H}_{3}\right)$ is satisfied for $\gamma_{k}=2^{-k+1}\left(\gamma^{*}=2\right)$ and

$$
F(x)=x^{\frac{1}{3}}+x^{-3} .
$$

By (97), we have

$$
f_{n}(t, u, v, w) \geq \frac{1}{n^{3} t^{\frac{1}{3}}(1+t)^{3}}\|u\|^{-2}, \quad \forall t \in J_{+}, u \in P_{+}, v, w \in P(n=1,2,3, \ldots)
$$

so, condition $\left(\mathrm{H}_{6}\right)$ is satisfied for

$$
c(t)=\frac{1}{t^{\frac{1}{3}}(1+t)^{3}} \quad\left(c^{*}=a^{*}<\frac{13}{8}\right)
$$

$\sigma(u)=\|u\|^{-2}$ and $u_{1}=\left(1, \ldots, \frac{1}{n^{3}}, \ldots\right)$. Moreover, (99) implies

$$
\begin{aligned}
& \|f(t, u, v, w)\| \geq\left(\sum_{n=1}^{\infty} \frac{1}{n^{3}}\right) \frac{1}{t^{\frac{1}{3}}(1+t)^{3}}\|u\|^{-2}>\frac{1}{t^{\frac{1}{3}}(1+t)^{3}}\|u\|^{-2}, \\
& \forall t \in J_{+}, u \in P_{+}, v, w \in P,
\end{aligned}
$$

so, (3) and (4) are satisfied, i.e., $f(t, u, v, w)$ is singular at $t=0$ and $u=\theta$. Similarly, (98) implies

$$
\left\|I_{k}(u)\right\| \geq\left(\sum_{n=1}^{\infty} \frac{1}{n^{3}}\right) 2^{-k}\|u\|^{-3}>2^{-k}\|u\|^{-3}, \quad \forall u \in P_{+}(k=1,2,3, \ldots),
$$

so, (5) is satisfied, i.e., $I_{k}(u)(k=1,2,3, \ldots)$ are singular at $u=\theta$. Similar to the discussion in Example 1, we can prove that $f\left(t, P_{p r}, P_{r}, P_{r}\right)$ and $I_{k}\left(P_{p r}\right)$ (for fixed $t \in J_{+}$and $r>p>0$; $k=1,2,3, \ldots)$ are relatively compact in $E=l^{1}$, so, condition $\left(\mathrm{H}_{4}\right)$ is satisfied. On the other hand, we have

$$
\begin{aligned}
& 0<\frac{g(x, y, z)}{x+y+z}= 2 \sqrt{3}\left(\frac{x}{x+y+z}\right)^{\frac{1}{2}}(x+y+z)^{-\frac{1}{2}}+x^{-2}(x+y+z)^{-1} \\
&+2\left(\frac{y}{x+y+z}\right)^{\frac{1}{2}}(x+y+z)^{-\frac{1}{2}}+2\left(\frac{z}{x+y+z}\right)^{\frac{1}{3}}(x+y+z)^{-\frac{2}{3}} \\
& \leq 2 \sqrt{3} x^{-\frac{1}{2}}+x^{-3}+2 x^{-\frac{1}{2}}+2 x^{-\frac{2}{3}}, \quad \forall x>0, y \geq 0, z \geq 0,
\end{aligned}
$$

so, (76) is satisfied. Moreover, it is clear that (77) is satisfied. Hence, our conclusion follows from Theorem 2. 


\section{Competing interests}

The authors declare that they have no competing interests.

\section{Authors' contributions}

All authors typed, read, and approved the final manuscript.

\section{Author details}

${ }^{1}$ School of Economics, Shandong University, Jinan, Shandong 250100, People's Republic of China. ${ }^{2}$ Department of Mathematics, Qilu Normal University, Jinan, Shandong 250100, People's Republic of China.

\section{Acknowledgements}

The author would like to thank Professor D. Guo for his valuable suggestions.

Received: 22 December 2012 Accepted: 18 March 2013 Published: 2 April 2013

\section{References}

1. Xian, X, O'Regan, D, Agarwal, RP: Multiplicity results via topological degree for impulsive boundary value problems under a non-well ordered upper and lower solution condition. Bound. Value Probl. 2008, Article ID 197205 (2008)

2. Agarwal, RP, Franco, D, O'Regan, D: Singular boundary value problems for first and second order impulsive differential equations. Aequ. Math. 69, 83-96 (2005)

3. Agarwal, RP, O'Regan, D: A multiplicity result for second order impulsive differential equations via the Leggett Williams fixed point theorem. Appl. Math. Comput. 161, 433-439 (2005)

4. Guo, D: Existence of positive solutions for nth-order nonlinear impulsive singular integro-differential equations in Banach spaces. Nonlinear Anal. 68, 2727-2740 (2008)

5. Guo, D: Positive solutions of an infinite boundary value problem for $n$ th-order nonlinear impulsive singular integro-differential equations in Banach spaces. Nonlinear Anal. 70, 2078-2090 (2009)

6. Guo, D: Some fixed point theorems of expansion and compression type with applications. In: Lakshmikantham, V (ed.) Nonlinear Analysis and Applications, pp. 213-221. Dekker, New York (1987)

7. Guo, D, Lakshmikantham, V: Nonlinear Problems in Abstract Cones. Academic Press, Boston (1988)

8. Guo, D, Lakshmikantham, V, Liu, XZ: Nonlinear Integral Equations in Abstract Spaces. Kluwer Academic, Dordrecht (1996)

9. Krasnoselskii, MA, Zabreiko, PP: Geometrical Methods of Nonlinear Analysis. Springer, New York (1984)

doi:10.1186/1687-2770-2013-69

Cite this article as: Chen and Qin: Multiple positive solutions for first-order impulsive singular integro-differential equations on the half line in a Banach space. Boundary Value Problems 2013 2013:69.

\section{Submit your manuscript to a SpringerOpen ${ }^{\odot}$ journal and benefit from:}

- Convenient online submission

- Rigorous peer review

- Immediate publication on acceptance

- Open access: articles freely available online

- High visibility within the field

- Retaining the copyright to your article 